\title{
Female Sexual Dysfunction and Timed Intercourse: A Prospective Study of 105 Infertile Women
}

\author{
Liuhong Cai ${ }^{* \#}$, Junxi Liu ${ }^{2 \#, ~ S h a o m i n ~ L u ², ~ J i a m i n ~ Y i n ~}{ }^{2}$ \\ ${ }^{1}$ Center for Reproductive Medicine, The Third Affiliated Hospital, Sun Yat-sen University, Guangzhou, China \\ ${ }^{2}$ School of Public Health, Sun Yat-sen University, Guangzhou, China \\ Email: *cailh@mail.sysu.edu.cn
}

Received 3 November 2015; accepted 21 November 2015; published 24 November 2015

Copyright (C) 2015 by authors and Scientific Research Publishing Inc.

This work is licensed under the Creative Commons Attribution International License (CC BY).

http://creativecommons.org/licenses/by/4.0/

c) (i) Open Access

\begin{abstract}
Introduction: Timed intercourse (TI) based on ovulation monitoring is an effective and common choice for treatment of infertility. However, TI related female sexual dysfunction remains to be elucidated. Method and Material: This was a prospective study and 105 infertile women were included using the Female Sexual Function Index (FSFI) to assess their sexual function in general sexual life (GSL) and TI cycle. Results: The mean age of the patients was $29.4 \pm 3.4$ years and the duration of infertility was $1.8 \pm 0.5$ years. The mean score of FSFI was 25.2 in GSL cycle and 24.5 in TI cycle $(p=0.008)$. Scores of 5 out of 6 domains of FSFI during GSL cycle were significantly higher than the counterparts during TI cycle. Female sexual function was related to stress, which mostly came from patients themselves and parents. The stronger the stress was, the more domains of FSFI were affected. Conclusion: Infertility is an important factor affecting female sexual function, especially TI condition reduced FSFI score in several domains, and this may be related to infertile stress.
\end{abstract}

\section{Keywords}

Infertility, Female Sexual Function, Timed Intercourse

\section{Introduction}

Infertility is defined by the World Health Organization (WHO) as the inability of sexually active couples to achieve pregnancy despite unprotected intercourse for a period greater than 12 months [1]. The prevalence of

\footnotetext{
*Corresponding author.

"These two authors contributed equally to this study.
}

How to cite this paper: Cai, L.H., Liu, J.X., Lu, S.M. and Yin, J.M. (2015) Female Sexual Dysfunction and Timed Intercourse: A Prospective Study of 105 Infertile Women. Advances in Reproductive Sciences, 3, 92-96. 
infertility ranges from $4 \%$ to $17 \%$ [2]. Specifically, the prevalence of infertility in Guangdong is $13.3 \%$ [3]. Incorrect timing of intercourse may affect a couple's ability to conceive, but timed intercourse (TI) may associate with adverse aspects. For example, the study showed that as the number of TI episodes increased, the number of men with erectile dysfunction and extramarital sex and those who wanted to avoid TI also increased [4]. The effect of TI on the female sexual function has not been thoroughly investigated. The aim of this study was to assess sexual function among infertile females who had progressed TI in the past 4 weeks.

\section{Material and Methods}

\subsection{Study Design}

The survey was conducted in the Center for Reproductive Medicine, the Third affiliated Hospital of Sun Yat-sen University, from January 2014 to September 2014. Infertile females visiting our department for the first time were interviewed for demographic information and medical history, and they were asked to fill the FSFI questionnaire independently. After workup of fertility assess, they were directed to conduct ovulation monitor and TI, and after that, they were asked to fill the FSFI questionnaire again. All participants gave a written informedconsent prior to participation. The study was conducted in accordance with the Declaration of Helsinki, and was approved by the Reproductive Ethics Committee of the Third Affiliated Hospital of Sun Yat-sen University.

\section{Inclusion and Exclusion Criteria}

Inclusive criteria included: 1) Infertile female at age of 22 - 40 years old; 2) married or have stable partner; 3) with active sexuality. Exclusion criteria for the study were: a) no sexual activity in the past 4 weeks; b) suffering from urinary tract infections, stones, cancer, mental illness, diabetes or thyroid dysfunction.

\subsection{Timed Intercourses}

We diagnosed ovulation based on menstrual cycle, cervico-vaginal mucus, urinary luteinizing hormone testing and ultrasound monitor. Patients implemented TI within 36 - 48 hours after injection of HCG.

\subsection{Quality Control}

The patients received standard training in filling out the questionnaire independently. The accuracy of our data was controlled by checking twice as soon as the interview was over. The data were double input into EpiData 3.1 (EpiData Association, Odense, Denmark) by two different technicians.

\subsection{Statistics Analysis}

Statistical analysis was performed using SPSS 19.0 (SPSS Inc, Chicago, IL, USA). Descriptive analysis was conducted using mean or percentage when appropriate. The demographic characteristics and the score of FSFI were compared using a t-test or Wilcoxon signed-rank test basing on the distribution of the data. And the associations were Spearman correlation coefficients. A p value which is less than 0.05 was considered statistically significant.

\section{Results}

\subsection{Characteristics of the Samples}

Totally 105 patients were included. The mean age of females was $29.4 \pm 3.4$ years, the mean body mass index (BMI) was $20.6 \pm 3.1$, the mean age of males was $32.3 \pm 5.8$ years, and the duration of infertility was $2.1 \pm 1.6$ years.

\subsection{Timed Intercourses Affecting Sexual Function of Females}

Significant difference was found regarding FSFI total scores, and also in arousal, orgasm and satisfaction domains, between general sexual life and timed-intercourse cycle (see Table 1).

\subsection{Source of Stress}

Pressure came from multiple aspects, particularly couples themselves and parents (see Table 2). 
Table 1. Comparing the scores of FSFI and its domains between GSL and TI cycle.

\begin{tabular}{cccc}
\hline & GSL & TI & p \\
\hline FSFI & $25.3(22.5-27.7)$ & $24.5(21.6-27.2)$ & 0.008 \\
FSFI $<26.55$ & $66(62.9 \%)$ & $67(63.8 \%)$ & 0.886 \\
Desire & $3.5(3.0-4.2)$ & $3.4(3.0-4.2)$ & 0.076 \\
Arousal & $3.9(3.3-4.5)$ & $3.7(3.3-4.2)$ & 0.001 \\
Lubrication & $4.6(3.7-5.4)$ & $4.5(3.6-5.4)$ & 0.057 \\
Orgasm & $3.9(3.2-4.8)$ & $3.8(3.2-4.4)$ & 0.043 \\
Satisfaction & $4.6(4.0-5.2)$ & $4.4(3.6-4.8)$ & 0.006 \\
Pain & $4.8(4.4-5.6)$ & $4.8(4.4-5.6)$ & 0.907 \\
\hline
\end{tabular}

GSL: general sexual life; TI: timed-intercourse; FSFI: female sexual function index.

Table 2. Source of mental pressure.

\begin{tabular}{cc}
\hline The source of mental pressure & Cases \\
\hline Self & 53 \\
Spouse & 17 \\
Parents & 30 \\
Parents-in-law & 39 \\
Friends & 11 \\
Others & 4 \\
\hline
\end{tabular}

\subsection{The Relationship between FSFI and Stress}

We divided stress into light, moderate and strong levels and found no significant difference between GSL and TI cycle regarding light stress and moderate stress, but significant difference was found regarding strong stress, including FSFI total scores and all of the six domains (see Table 3).

\section{Discussion}

Fertility is an important factor inducing female sexual dysfunction. Female sexual dysfunction is recognized as a widespread health problem with a prevalence rate between $30 \%$ and $52 \%$ in Asian countries [5]. The FSFI, a total score of more than 28 was considered to be indicative of normal female sexual function and a total score of less than 28 was considered to be indicative of female sexual dysfunction (FSD) [6] [7]. In the past study, half of the women reported that infertility was the most stressful experience of their lives [8]. Both the diagnosis and treatments for infertility are associated with psychological stress [9]. This study showed that the total scores of infertile females' FSFI were 25.3 (22.5 - 27.7, general intercourse cycle) and 24.5 (21.6 - 27.2, timed-intercourse cycle). FSD was $79.0 \%$ in GSL cycle and $81.0 \%$ in TI cycle for infertile females, which is much higher than the infertile females in Oregon, USA (37.3\%) [6] and the infertile women in California, USA (40\%) [10]. In our study, all of the participants reported stress, though with different level. A previous study showed that FSD proved to be much more sensitive to variations in distress among women with infertility than general distress and those with primarily infertility would have higher levels of FSD than women with secondary infertility [11].

Timed-intercourse is a very stressful factor for infertile women. Study showed that much of the fertile possibility during the menstrual cycle was missed if coitus was timed with menstrual calendar [12], so many couples chose to monitor ovulation by B ultrasound. Besides, recent study has reported that a history of previous infertility treatments was a risk factor for sexual dysfunction in infertile females [13]. Anxiety about the possibility of getting pregnant may change sexual function with a potential impact on women's quality of life [14]. Due to the traditional conception, there was lack of personal and clinical attention paid to the sexual problem among the 
Table 3. FSFI domaint scores relate to self-reported stress.

\begin{tabular}{|c|c|c|c|c|c|c|c|c|c|}
\hline \multirow{3}{*}{ Stress } & \multirow{2}{*}{\multicolumn{2}{|c|}{$\begin{array}{l}\text { Light stress } \\
\qquad \mathrm{N}=25\end{array}$}} & \multirow{3}{*}{$\mathrm{p}$} & \multirow{2}{*}{\multicolumn{2}{|c|}{$\begin{array}{c}\text { Moderate stress } \\
\qquad \mathrm{N}=60\end{array}$}} & \multirow{3}{*}{$\mathrm{p}$} & \multirow{2}{*}{\multicolumn{2}{|c|}{$\begin{array}{c}\text { Strong stress } \\
\qquad \mathrm{N}=20\end{array}$}} & \multirow{3}{*}{$\mathrm{p}$} \\
\hline & & & & & & & & & \\
\hline & GSL & TI & & GSL & TI & & GSL & TI & \\
\hline FSFI & $\begin{array}{c}24.1 \\
(21.6-26.1)\end{array}$ & $\begin{array}{c}23.8 \\
(21.6-26.8)\end{array}$ & 0.960 & $\begin{array}{c}26.0 \\
(22.8-28.8)\end{array}$ & $\begin{array}{c}25.5 \\
(22.2-28.2)\end{array}$ & 0.260 & $\begin{array}{c}24.9 \\
(23.0-26.7)\end{array}$ & $\begin{array}{c}23.5 \\
(21.0-26.4)\end{array}$ & 0.001 \\
\hline Desire & $\begin{array}{c}3.3 \\
(3.0-3.6)\end{array}$ & $\begin{array}{c}3.6 \\
(3.0-4.2)\end{array}$ & 0.320 & $\begin{array}{c}3.7 \\
(3.0-4.2)\end{array}$ & $\begin{array}{c}3.6 \\
(3.0-4.2)\end{array}$ & 0.180 & $\begin{array}{c}3.5 \\
(3.0-4.0)\end{array}$ & $\begin{array}{c}3.1 \\
(2.4-3.6)\end{array}$ & 0.020 \\
\hline Arousal & $\begin{array}{c}3.7 \\
(3.3-3.9)\end{array}$ & $\begin{array}{c}3.4 \\
(3.3-3.9)\end{array}$ & 0.220 & $\begin{array}{c}4.0 \\
(3.3-4.5)\end{array}$ & $\begin{array}{c}3.9 \\
(3.3-4.2)\end{array}$ & 0.040 & $\begin{array}{c}3.8 \\
(3.1-4.4)\end{array}$ & $\begin{array}{c}3.4 \\
(2.7-3.9)\end{array}$ & 0.004 \\
\hline Lubrication & $\begin{array}{c}4.5 \\
(3.6-5.4)\end{array}$ & $\begin{array}{c}4.5 \\
(3.6-5.4)\end{array}$ & 0.580 & $\begin{array}{c}4.7 \\
(3.9-5.4)\end{array}$ & $\begin{array}{c}4.7 \\
(3.9-5.7)\end{array}$ & 0.970 & $\begin{array}{c}4.5 \\
(3.6-5.6)\end{array}$ & $\begin{array}{c}4.3 \\
(3.3-5.4)\end{array}$ & 0.018 \\
\hline Orgasm & $\begin{array}{c}3.7 \\
(3.2-4.0)\end{array}$ & $\begin{array}{c}3.5 \\
(3.2-4.0)\end{array}$ & 0.100 & $\begin{array}{c}4.2 \\
(3.6-5.2)\end{array}$ & $\begin{array}{c}4.0 \\
(3.6-4.8)\end{array}$ & 0.190 & $\begin{array}{c}3.7 \\
(3.2-4.0)\end{array}$ & $\begin{array}{c}3.6 \\
(2.8-4.0)\end{array}$ & 0.330 \\
\hline Satisfaction & $\begin{array}{c}4.2 \\
(3.6-4.8)\end{array}$ & $\begin{array}{c}4.1 \\
(3.6-4.8)\end{array}$ & 0.290 & $\begin{array}{c}4.6 \\
(4.0-5.2)\end{array}$ & $\begin{array}{c}4.5 \\
(3.6-5.2)\end{array}$ & 0.150 & $\begin{array}{c}4.5 \\
(4.0-4.8)\end{array}$ & $\begin{array}{c}4.3 \\
(3.7-4.8)\end{array}$ & 0.060 \\
\hline Pain & $\begin{array}{c}4.7 \\
(3.6-5.2)\end{array}$ & $\begin{array}{c}4.7 \\
(3.6-5.2)\end{array}$ & 1.000 & $\begin{array}{c}4.9 \\
(4.4-5.6)\end{array}$ & $\begin{array}{c}4.9 \\
(4.4-5.6)\end{array}$ & 0.970 & $\begin{array}{c}4.9 \\
(4.4-5.6)\end{array}$ & $\begin{array}{c}4.8 \\
(4.4-5.9)\end{array}$ & 0.710 \\
\hline
\end{tabular}

infertile females. The pressures were compounded when sexual intercourse was expected during special time of menstrual cycle and when its objectives were more oriented towards conception than an expansion of loving relationship [15]. And our study indicated that desire disorder and arousal disorder were more affected which coincided with the previous study [15].

Significantly differences were found between the strong stress and the moderate stress (FSFI: $p=0.025$; Lubrication: $p=0.042$ ). When the pressure increased beyond what they could handle, it became a negative factor to female sexual function.

We found that the infertile females may get higher risks of being FSD especially in the domains of desire, arousal and lubrication in the strong stress group. It is worthy to notice that arousal disorder is more likely to occur in not only the mild stress group but in the strong stress group.

The results of the present study should be interpreted with recognition of its limitations. First, the amount of our samples was limited which may bias the outcomes and conclusions. Second, recall bias must existed, because not all of the patients were sensitive enough to recall their real feeling during GSL and TI. Third, cultural factors such as shyness and embarrassment of Chinese women led to inadequate identification and management of these problems.

\section{Conclusion}

Infertility is an important factor affecting female sexual function, especially TI condition reduces FSFI score in several domains, and this may be related to infertile stress.

\section{Conflicts of Interests}

None declared.

\section{Acknowledgements}

Project supported by the National Science Foundation, No. 81170533.

\section{References}

[1] Zegers-Hochschild, F., Adamson, G.D., de Mouzon, J., Ishihara, O., Mansour, R., Nygren, K., et al. (2009) The International Committee for Monitoring Assisted Reproductive Technology (ICMART) and the World Health Organization (WHO) Revised Glossary on ART Terminology. Human Reproduction, 24, 2683-2687. http://dx.doi.org/10.1093/humrep/dep343

[2] Rosen, R.C., Revicki, D.A. and Sand, M. (2014) Commentary on "Critical Flaws in the FSFI and IIEF". Journal of Sex 
Research, 51, 492-497. http://dx.doi.org/10.1080/00224499.2014.894491

[3] Huang, J.-T. (2013) The Analysis of Infertility and Its Influencing Factors of the Married Couples in Guangdong Province. Chinese Journal of Public Health, 2, 194-198.

[4] Bak, C.W., Lyu, S.W., Seok, H.H., Byun, J.S., Lee, J.H., Shim, S.H., et al. (2012) Erectile Dysfunction and Extramarital Sex Induced by Timed Intercourse: A Prospective Study of 439 Men. Journal of Andrology, 33, 1245-1253. http://dx.doi.org/10.2164/jandrol.112.016667

[5] Zhang, H. and Yip, P.S. (2012) Female Sexual Dysfunction among Young and Middle-Aged Women in Hong Kong: Prevalence and Risk Factors. The Journal of Sexual Medicine, 9, 2911-2918. http://dx.doi.org/10.1111/j.1743-6109.2012.02773.x

[6] Furukawa, A.P., Patton, P.E., Amato, P., Li, H. and Leclair, C.M. (2012) Dyspareunia and Sexual Dysfunction in Women Seeking Fertility Treatment. Fertility and Sterility, 98, 1544-1548. http://dx.doi.org/10.1016/i.fertnstert.2012.08.011

[7] Jaafarpour, M., Khani, A., Khajavikhan, J. and Suhrabi, Z. (2013) Female Sexual Dysfunction: Prevalence and Risk Factors. Journal of Clinical and Diagnostic Research, 7, 2877-2880.

[8] Freeman, E.W., Boxer, A.S., Rickels, K., Tureck, R. and Mastroianni, L.J. (1985) Psychological Evaluation and Support in a Program of in Vitro Fertilization and Embryo Transfer. Fertility and Sterility, 43, 48-53.

[9] Greenfeld, D.A. (1997) Does Psychological Support and Counseling Reduce the Stress Experienced by Couples Involved in Assisted Reproductive Technology? Journal of Assisted Reproduction and Genetics, 14, 186-188. http://dx.doi.org/10.1007/BF02766107

[10] Millheiser, L.S., Helmer, A.E., Quintero, R.B., Westphal, L.M., Milki, A.A. and Lathi, R.B. (2010) Is Infertility a Risk Factor for Female Sexual Dysfunction? A Case-Control Study. Fertility and Sterility, 94, 2022-2025. http://dx.doi.org/10.1016/j.fertnstert.2010.01.037

[11] Greil, A.L., Shreffler, K.M., Schmidt, L. and McQuillan, J. (2011) Variation in Distress among Women with Infertility: Evidence from a Population-Based Sample. Human Reproduction, 26, 2101-2112. http://dx.doi.org/10.1093/humrep/der148

[12] Agarwal, S.K. and Haney, A.F. (1994) Does Recommending Timed Intercourse Really Help the Infertile Couple? Obstetrics \& Gynecology, 84, 307-310.

[13] Turan, V., Kopuz, A., Ozcan, A., Kocakaya, B., Sahin, C. and Solmaz, U. (2014) Sexual Dysfunction in Infertile Turkish Females: Prevalence and Risk Factors. European Journal of Obstetrics \& Gynecology and Reproductive Biology, 182, 128-131. http://dx.doi.org/10.1016/j.ejogrb.2014.09.013

[14] Li, R.H., Lo, S.S., The, D.K., Tong, N.C., Tsui, M.H., Cheung, K.B., et al. (2004) Impact of Common Contraceptive Methods on Quality of Life and Sexual Function in Hong Kong Chinese Women. Contraception, 70, 474-482. http://dx.doi.org/10.1016/j.contraception.2004.06.010

[15] Jain, K., Radhakrishnan, G. and Agrawal, P. (2000) Infertility and Psychosexual Disorders: Relationship in Infertile Couples. Indian Journal of Medical Sciences, 54, 1-7. 